\title{
黄土丘陵沟壑区生态风险时空动态及其风险分区 以陕西省米脂县为例
}

\author{
刘迪, 陈海, 史琴琴, 张行, 耿甜伟
}

(西北大学城市与环境学院/陕西省地表系统与环境承载力重点实验室,西安 710127)

\begin{abstract}
摘要: 目前, 黄土丘陵沟壑区等生态脆弱区生态风险评估已成为地理学与生态学应对生态系 统管理的研究热点之一。以黄土丘陵沟壑区米脂县为研究区, 构建“风险概率一敏感性一损失 度” (PSI) 的三维评价框架, 并以子流域为评价单元进行数据整合, 分析了米脂县 2009-2015 年 准则层与综合生态风险的时空分异及其重心转移, 并基于风险主导因子给出米脂县风险防范 分区及降险对策。结果如下: (1)2009-2015 年风险概率分别为 49.93\%、52.92\%, 有上升趋势; 生 境敏感性分别为 $0.61 、 0.60$,下降了 $1.6 \%$, 生境质量趋好; 损失度分别为 $0.42 、 0.46$, 损失度增 加。(2)生态风险呈现中间高南北低的空间分布; 研究期间生态风险值分别为 $0.14 、 0.15$, 风险有 所升高; 风险重心向西南转移跃人银州川道且风险演化主体方向为西北一东南走向。(3)风险 预警区、生态恢复区、预警恢复兼顾区、自然调控区面积占比分别为 $7.53 \% 、 6.57 \% 、 23.86 \%$ 、 $62.04 \%$ 。基于风险主导因子的风险防范分区可有效进行风险消解, 促进区域生境的可持续。
\end{abstract}

关键词：生态风险;时空分异; 风险重心; 风险分区; 米脂县;黄土丘陵沟壑区

目前，地球已进人 “人类世” 新纪元，人类在控制社会经济走向、改变地球表面环 境的同时深刻影响地球表层系统演化与发展 ${ }^{[1]}$ 。土地利用变化背景下全球景观格局及其生 态系统效应产生关联性变化, 并在异源胁迫下引致诸多生态风险 ${ }^{[2]}$ 。对生态风险的科学认 识与评估, 已成为当前地理学与生态学应对社会一生态系统综合管理的热点研究方向 之一 ${ }^{[3]}$ 。

生态风险是指生态系统及其组分暴露于自然灾害、人类活动等非期望事件下产生的 可能性后果 ${ }^{[2,4]}$, 包括风险源、暴露一响应过程、风险受体等评价要素 ${ }^{[5]}$ 。生态风险评价 （Ecological Risk Assessment, ERA) 起步于 20 世纪 80 年代, 起初面向化学污染物对人体 健康的影响 ${ }^{[6-7]}$, 由于风险源的复杂性与受体的多样性, 风险评价逐渐扩展至多源多受体 的社会经济一自然复合生态系统范畴 ${ }^{[5]}$ 。当前风险研究多基于风险源汇或基于景观结构进 行评价 ${ }^{[8]}$, 范式均为概率与损失的综合表征 ${ }^{[9]}$ 。基于源汇的风险视角能够快速识别威胁区 域生态系统的风险源并明确风险受体 ${ }^{[10-12]}$, 较为全面地展现区域环境的空间差异, 但多为 单一时间截面分析而缺乏对风险时序演化的探讨。基于景观指数的风险评价依托于过程 与格局的耦合关联, 更加注重风险的时空异质性 ${ }^{[13]}$, 并在流域 ${ }^{[14-16]}$ 、海岸带 ${ }^{[17-18]}$ 、矿区 ${ }^{[19] 、}$ 行 政区 ${ }^{[8,13,20]}$ 等诸多区域取得应用，但在格局视角下难以表征诸多风险源汇要素从而阻碍了 评价结果的实用性 ${ }^{[9,21]}$ 。总的来看, 融合多源汇层次的风险框架缺少要素时序的度量, 同

收稿日期：2018-12-29; 修订日期：2019-04-02

基金项目：国家自然科学基金项目（41671086，41871185）

作者简介：刘迪（1993-), 男, 河南郑州人, 博士研究生, 研究方向为综合自然地理与景观生态。

E-mail: 1cx@stumail.nwu.edu.cn

通讯作者：陈海（1971- ), 男, 山西侯马人, 博士, 教授, 研究方向为土地利用与农户行为。E-mail: chw@nwu.edu.cn 
时格局风险方法面临源汇要素表征困难的瓶颈，因此在识别风险源与受体损失的同时突 出格局损失对受体的贡献程度 ${ }^{[12]}$ ，并以此探讨风险的时序特征则成为风险评估的关键。 另外，在 “概率一损失” 的二维风险框架下，当前风险分析高度关注源汇要素的识别及 度量, 缺乏从源到受体暴露一响应过程的显性表征。从风险因果链视角分析, 生境是受 体暴露于风险源的外部环境 ${ }^{[1]}$, 是风险源引发受体响应的中间过程，并隐含区域格局与 过程的互馈[5]。受体遭受风险源影响时敏感性的大小能够体现生境中风险的暴露一响应过 程, 可通过生境质量（Habitat Quality）评估加以完善 ${ }^{[22]}$, 因此通过链接生境敏感性完善 风险因果链，可从风险框架角度聚合复杂风险要素并揭示其发生机理 ${ }^{[5]}$ 。

基于此，本文以地处黄土沟壑区的米脂县为例，关注多源胁迫与损失受体的同时链 接生境质量作为风险源汇的中间环节，构建 “风险概率一敏感性一损失度” 的三维风险 框架，通过审视源汇中间过程中系统结构与功能互作及格局与过程的互馈关系，为风险 框架构建中信息的丰富化提供支撑，在此基础上探讨风险要素的时序动态，同时，基于 子流域设定风险主导区并给出降险对策，可为区域风险消减与可持续发展提供借鉴。

\section{1 研究方法与数据来源}

\section{1 研究区概况}

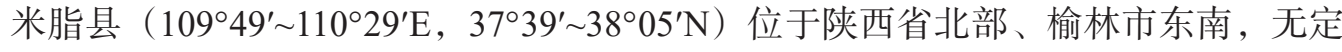
河中游（图 1), 面积 $1178 \mathrm{~km}^{2}$, 属黄土丘陵沟壑区。全县分为三个地貌区：（1）西北部 为梁峁丘陵区。该区与沙质荒漠化区接壤, 水土流失严重; (2) 东部崩状沟壑区。以黄 土卲为主, 沟坡最深, 地表破碎;（3）中部河谷川道区。河谷地势平坦，水土流失轻 微, 是全县经济区。属中温带半干旱气候带, 雨热同期, 受气候扰动影响, 干旱灾害发 生频次较高。耕地、林草地为主要土地利用类型; 山地主要种植果树经济林, 置耕梯田 及川坝地种植粮食与经济作物, 有谷子、洋芋、玉米、杂粮等, 构成多样性生产景观。 作为典型农耕区与生态脆弱区，深度农耕行为辅以农业化学投人致使县域农业生态系统 呈现脆弱性特征, 亟需对风险 变化趋势做出把握以辅助风险 管理。2009年第一轮退耕的结 束，标示着生态建设进入新阶 段, 在城镇化推进、社会经济 转型驱动下, 耕林转化与撂荒 行为频发, 地类及景观配置变 化明显, 为揭示风险的演化提 供了案例基础。

\section{2 数据来源与处理}

研究涉及 DEM 数字高程、 土地利用类型数据及社会经济 统计资料等基础数据。米脂县 2009年地类数据来源于第二次 全国土地利用 $1: 1$ 万调查数据

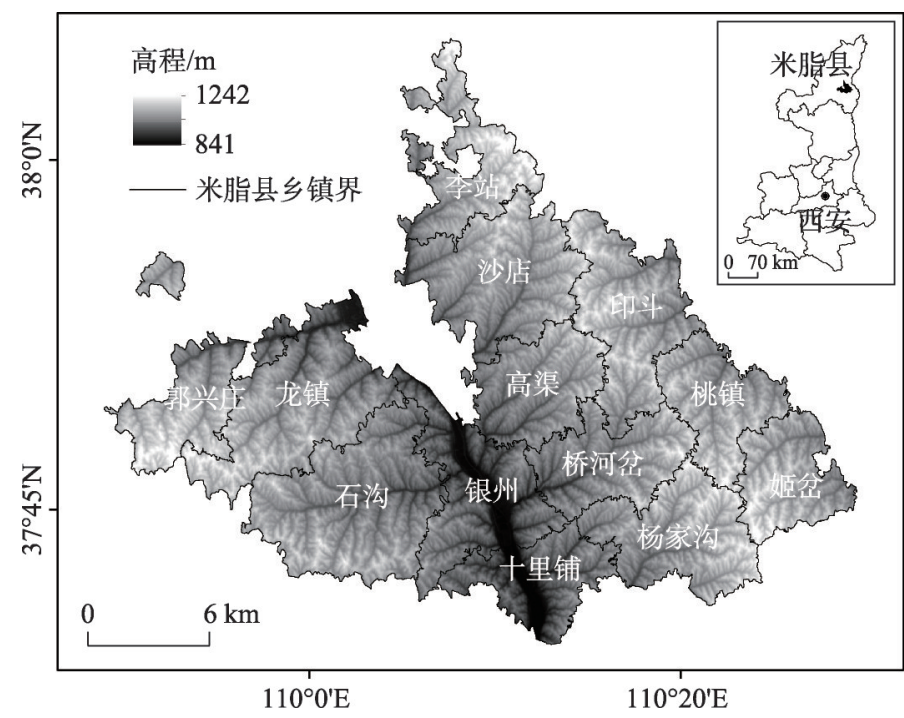

图 1 米脂县地理位置及其数字高程

Fig. 1 Location and DEM of Mizhi county 
集。2015 年土地利用类型数据以该年高分一号影像为数据源，在ENVI 5.1 软件背景下结 合 2009 年米脂县地类矢量结果进行监督分类和目视解译获取，解译 Kappa 指数达到 0.86。参照全国土地利用现状分类标准（GB/T21010-2017），将二级地类归并为耕地、果 园、林地、草地、水域、建设用地、荒地 7 类一级地类, 重采样为 $10 \mathrm{~m}$ 土地利用栅格用 于后续时序对比。DEM数据来源于地理空间数据云ASTER GDEMS 数据集 $30 \mathrm{~m}$ DEM栅 格 (http://www.gscloud.cn/)，通过 GPS 测点，插值重采样为 $10 \mathrm{~m} \mathrm{DEM}$ 。利用 ArcGIS 10.2 水文分析模块提取研究区子流域范围, 共划分 253 个子流域作为评价单元, 流域单 元内评价结果取境内所有栅格均值 ${ }^{[5]}$ 。人口密度、粮食产量及农业投人等社会经济数据源 自《米脂县社会经济统计年鉴》(2009-2015 年)。

\section{3 研究方法}

\subsection{1 综合生态风险模型构建}

本文基于风险因果链模型识别风险源、暴露一响应过程及风险受体 ${ }^{[5]}$, 构建 “综合生 态风险（Comprehensive Ecological Risk，CER）=风险概率（Risk Probability，RP）×敏 感性（Sensibility，S） ×损失（Impartment，I）”的生态风险三维框架，继而选用典型指 标对模型具体化 ${ }^{[16,22-23]}$ 。公式如下:

$$
C E R=\sum_{i=1}^{n} P \times S \times I
$$

式中： $n$ 为子流域数量。风险概率聚焦自然灾害与农耕生产引致的风险胁迫，包括干旱 风险、洪涝风险、土壤污染风险、外部距离风险。敏感性基于InVEST模型生境质量模块 评估来表征。损失度基于自然一社会系统损失度定量核算，包括景观损失指数、人口密 度、粮食产量。

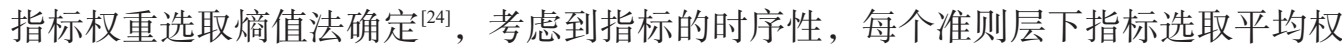
重值作为最终权重，公式如下：

$$
\begin{gathered}
P_{i j}=S_{i} / S_{i j} \\
e_{j}=-(1 / \ln n) \times \sum P_{i j} \ln P_{i j} \\
g_{j}=1-e_{j} \\
w_{j}=g_{j} / \sum g_{j}
\end{gathered}
$$

\begin{tabular}{|c|c|c|c|c|c|c|c|c|}
\hline 准则层 & \multicolumn{4}{|c|}{ 风险概率 } & \multirow{2}{*}{$\begin{array}{c}\text { 敏感性 } \\
\text { 生境质量 }\end{array}$} & \multicolumn{3}{|c|}{ 损失度 } \\
\hline 指标层 & 干早 & 洪港 & 土壤污染 & 外部距离 & & 景观格局指数 & 人口密度 & 粮食产量 \\
\hline 权重 & 0.34 & 0.30 & 0.21 & 0.15 & 1 & 0.58 & 0.22 & 0.20 \\
\hline
\end{tabular}

式中： $i$ 为指标层指标; $j$ 为准则层指标; $S_{i} 、 S_{i j}$ 为指标标准化值; $P_{i j}$ 为矩阵 $; e_{j}$ 为指标的 信息熵; $g_{j}$ 为差异性系数; $w_{j}$ 为指标权重。熵值法计算结果示于表 1 。

表 1 指标层权重

Table 1 Weight of index layers

\section{(1) 风险概率}

本文基于干旱、洪涝孕灾环境与土地地类生态特性实现自然灾害空间显示。其中， 选取高程与汇水面积说明干旱胁迫的孕灾环境; 选取高程、距水域距离说明洪涝胁迫的 孕灾环境；同时，不同地类遭遇干旱、洪涝风险的敏感性不同 ${ }^{[25-26]}$ 。公式如下: 


$$
\begin{gathered}
D R P=\frac{E L E}{A W A} \times D V_{i} \\
F R P=\frac{1}{E L E \times D W} \times F V_{i}
\end{gathered}
$$

式中: $E L E$ 为高程; $A W A$ 为汇水面积; $D W$ 为距水域距离; $D V_{i}$ 与 $F V_{i}$ 分别为不同地类遭遇 干旱、洪涝风险的敏感性。借鉴已有研究 ${ }^{[25-26]}$, 干旱、洪涝风险下土地利用脆弱程度见 表2。

表 2 自然灾害风险下土地利用类型的脆弱程度

Table 2 Vulnerability of land use types under natural disaster risks

\begin{tabular}{cccccccc}
\hline 风险类型 & 耕地 & 果园 & 林地 & 草地 & 水域 & 建设用地 & 荒地 \\
\hline 干旱 & 7 & 6 & 5 & 4 & 3 & 1 & 2 \\
洪涝 & 7 & 6 & 2 & 3 & 1 & 5 & 4 \\
\hline
\end{tabular}

黄土农耕区内土地类型及质量由农户深度农耕所改造，且关联诸多生态问题 ${ }^{[14]}$ ，并 引发农耕风险, 本文从土壤污染胁迫、外部距离胁迫两个方面表征 ${ }^{[27]}$ 。米脂县为农业大 县, 环境污染应关注农业土壤污染, 以子流域内耕地面积比例为权重选取农塑薄膜覆盖 密度、农药化肥施用强度刻画农耕行为对土壤质量的影响 ${ }^{[28]}$ 。外部距离胁迫是不同地类 对农户干扰响应程度的刻画 ${ }^{[27]}$ 。距离道路越远，坡度越高，不同地类代表的生态系统在 农户干扰下其生态系统服务降低的可能性越小 ${ }^{[1]}$ 。公式如下 ${ }^{[22,29]}$ :

$$
\begin{gathered}
\text { slope }=\left\{\begin{array}{l}
1, \text { slope } \leqslant 5^{\circ} \\
-0.05 \text { slope }+1.25,5^{\circ}<\text { slope }<25^{\circ} \\
0, \text { slope } \geqslant 25^{\circ}
\end{array}\right. \\
\text { Road }=\frac{1}{1+\left(d / a_{i}\right)}
\end{gathered}
$$

式中: $d$ 为地类栅格与道路的最短距离; $a_{i}$ 为距离衰减系数, 表示不同地类对道路的依赖 程度, 借鉴已有研究 ${ }^{[29]}$, 针对建筑用地、耕地、果园、水域、草地、林地和荒地, $a_{i}$ 分别 取 $1000 、 500 、 500 、 100 、 10 、 1 、 1$ 。

（2）生境敏感性

生境敏感性表征生境面对多源风险表现出的易损性质 ${ }^{[16]}$ ，可作为风险受体暴露于风 险源下的直接响应。区域生境是否敏感与风险源威胁距离、生境自身的易损属性相关, 对这些要素的整合量化与空间显示，是进行生境敏感性表征的关键 ${ }^{[22]}$ 。InVEST 模型是目 前较为成熟且应用最多的生态系统服务评估模型 ${ }^{[30]}$, 选取其中的生境质量模块表征敏感 性。生境质量是指生境提供给物种生存繁衍所需条件的潜力, 即生境质量越好的区域, 物种及生境在多源胁迫下自我恢复的能力越高, 敏感性就越低, 反之亦然。模块计算公 式见文献 [22, 31]。模型包含三个变量：胁迫因子影响距离、生境的胁迫敏感度、生境与 胁迫源的距离 ${ }^{[32]}$, 且胁迫因子对生境的影响随距离的缩减均呈指数型递增。威胁因子与 生境类型选择、最大影响距离与敏感度设置综合考虑模型使用说明 ${ }^{[33]}$ 及已有研究 ${ }^{[22,34]}$, 结 果示于表3。

(3) 系统损失度

在风险评价中，多生态终点的交互作用被广泛关注 ${ }^{[21]}$, 风险损失更偏向自然一社会 经济的综合量化, 本文通过自然一社会经济损失度进行核算 ${ }^{[12,27]}$ 。高强度农耕行为对脆弱 
表 3 生境类型对威胁因子的敏感度、威胁因子最大影响距离及权重

Table 3 Sensitivity of habitat types to threat factors, maximum distance of influence and weights of threat factors

\begin{tabular}{|c|c|c|c|c|c|c|}
\hline \multirow{2}{*}{ 生境类型 } & \multirow{2}{*}{ 生境适宜度 } & \multicolumn{5}{|c|}{ 威胁因子 } \\
\hline & & 居住地 & 交通用地 & 工矿用地 & 荒地 & 耕地 \\
\hline 水域 & 0.9 & 0.9 & 0.85 & 0.9 & 0.4 & 0.3 \\
\hline 果园 & 0.3 & 0.5 & 0.5 & 0.5 & 0.3 & 0.3 \\
\hline 林地 & 1.0 & 0.75 & 0.7 & 0.8 & 0.5 & 0.75 \\
\hline 草地 & 0.6 & 0.55 & 0.5 & 0.55 & 0.8 & 0.35 \\
\hline \multicolumn{2}{|c|}{ 最大影响距离/km } & 0.8 & 0.8 & 1.0 & 0.25 & 0.25 \\
\hline \multicolumn{2}{|l|}{ 权重 } & 1.0 & 0.6 & 0.4 & 0.05 & 0.2 \\
\hline
\end{tabular}

自然本底的干扰，使景观类型暴露于多种风险源之下，由此引致的生态系统服务损失可 通过景观结构和功能的变化得以体现 ${ }^{[3]}$ 。本文以子流域为评价单元，利用景观损失指数 （Landscape Impartment Index，LII）反映风险受体暴露于人为干扰时其自然属性损失的 程度。公式如下:

$$
L I I_{k}=\sum_{i=1}^{n} \frac{S_{k i}}{S_{k}} \sqrt{E_{i} \times F_{i}}
$$

式中: $L I I_{k}$ 为子流域 $k$ 的景观损失指数; $n$ 为景观类型数量; $k$ 为子流域数量; $E_{i}$ 与 $F_{i}$ 分别 为地类 $i$ 的干扰度、脆弱度; $S_{k i}$ 为子流域 $k$ 内地类 $i$ 的面积; $S_{k}$ 为子流域 $k$ 的面积。干扰度 $E_{i}$ 各项指标在 Fragstats 4.2 中计算, 指标含义及计算方法见文献 [20, 22]。脆弱度表示景 观类型内部结构的易损性，借鉴已有研究 ${ }^{[2,27]}$, 将脆弱性分为 7 个等级, 求和标准化处理 后脆弱度由低到高分别为建设用地 0.04 , 林地 0.07 , 草地 0.11 , 果园 0.14 , 耕地 0.18 , 水 域 0.21 , 荒地 0.25 。

农耕区社会经济系统中, 劳动力是区域发展的根本, 粮食资产是农户福祉得以实现 的基础部分, 两者是风险胁迫下最为敏感的社会经济损失受体，利用人口密度、粮食产 量指标综合反映。依托于土地利用数据, 分别以子流域内建设用地比例、耕地面积比例 为权重, 分别结合乡镇人口密度标准值、乡镇粮食产量标准值进行分区统计获取人口密 度、粮食产量空间分布 ${ }^{[27]}$ 。

\subsection{2 标准差椭圆及其风险重心}

标准差椭圆（Standard Deviational Ellipse，SDE）在空间统计领域应用广泛，用于探 索地理要素空间分布的全局特征。本文标准差栯圆以研究区不同时期生态风险平均中心 为重心，分别计算2009-2015年综合生态风险的时序籿圆，并将椭圆圆心作为风险重心特 征值描述风险的时空跃迁及其重心转移 ${ }^{[13]}$ 。利用 ArcGIS 10.2方向分布模块以风险值为权 重计算标准差栯圆，模型参数选择第一级（椭圆大小涵盖风险数值的 $68 \%$ )。

\subsection{3 风险防范分区}

风险防范分区是指在风险评价的基础上，针对风险等级及其主导因子差异，划分风 险因子主导 ${ }^{[1]}$ 。本文基于流域尺度风险概率与敏感性、综合生态风险等级开展风险空 间分区。致灾因子与孕灾环境是风险防范的主要考量因素, 损失度不在考虑范围之内 ${ }^{[5]}$ 。 这是由于在生态脆弱的黄土沟壑区内，生态系统的恢复与重建更利于风险的消减与可持 续性的提高, 若自然灾害与农耕活动干扰下生态系统遭受破坏, 必然导致景观结构的无 序及区域生产力的下降，因而风险防范应从导致风险的灾害成因及敏感性人手，着力降 
低风险概率及生境敏感性。

基于以上考虑，以小流域为单元，依托于 2015 年生态风险评价结果，对 $C E R 、 R P$ 、 $S$ 分别求取全区均值, 按照三者与各自均值的高低组合特征进行分区划分 ${ }^{[5]}$, 将 253 个子 流域划分为 4 种风险类型：高 $C E R$ 、高 $R P$ 、低 $S$ 流域中风险防范以 $R P$ 为主导，为风险预 警区; 高 $C E R$ 、低 $R P$ 、高 $S$ 流域为生态恢复区，以 $S$ 为主导; 高 $C E R$ 、高 $R P$ 、高 $S$ 流域 为预警恢复兼顾区，强调 $R P-S$ 的综合防范; 高 $C E R$ 、低 $R P$ 、低 $S$ 的流域以及全部低风险 流域, 由于主导因子不明或风险较低, 划为防范冷点, 主要依托生态系统自身恢复力抵 御外部风险, 为自然调控区。

\section{2 结果分析}

基于 ArcGIS 10.2 空间叠加分别得到风险概率、敏感性、损失度及生态风险评估结 果, 通过自然断点法分级, 分级结果示于表 4, 为使时序要素之间具备可比性, 将研究 末期各等级间断点与研究初期统一，空间化结果分别如图2 图 5 所示。

\section{1 准则层要素时空分异}

\subsection{1 风险概率时空分异}

米脂县 2009 年、 2015 年风险概率分别为 $49.93 \%$ 、 $52.92 \%$ ，上升 $5.97 \%$ 。图 2 中，风 险概率呈现西北部低、中部与东部较高的空间格局。图 $2 \mathrm{a}$ 中, V 级风险概率面积占比

表 4 单一准则层与综合生态风险分级标准

Table 4 The classification standard of criteria layers and comprehensive ecological risk

\begin{tabular}{ccccc}
\hline 等级划分 & 风险概率 $/ \%$ & 敏感性 & 损失度 & 生态风险 \\
\hline I & $34.25 \sim 43.12$ & $0.38 \sim 0.51$ & $0.21 \sim 0.32$ & $0.03 \sim 0.10$ \\
II & $43.13 \sim 48.07$ & $0.52 \sim 0.58$ & $0.33 \sim 0.40$ & $0.11 \sim 0.13$ \\
III & $48.08 \sim 53.30$ & $0.59 \sim 0.65$ & $0.41 \sim 0.47$ & $0.14 \sim 0.17$ \\
IV & $53.31 \sim 59.70$ & $0.66 \sim 0.81$ & $0.48 \sim 0.55$ & $0.18 \sim 0.23$ \\
V & $59.71 \sim 71.32$ & $0.82 \sim 0.99$ & $0.56 \sim 0.74$ & $0.24 \sim 0.36$ \\
\hline
\end{tabular}

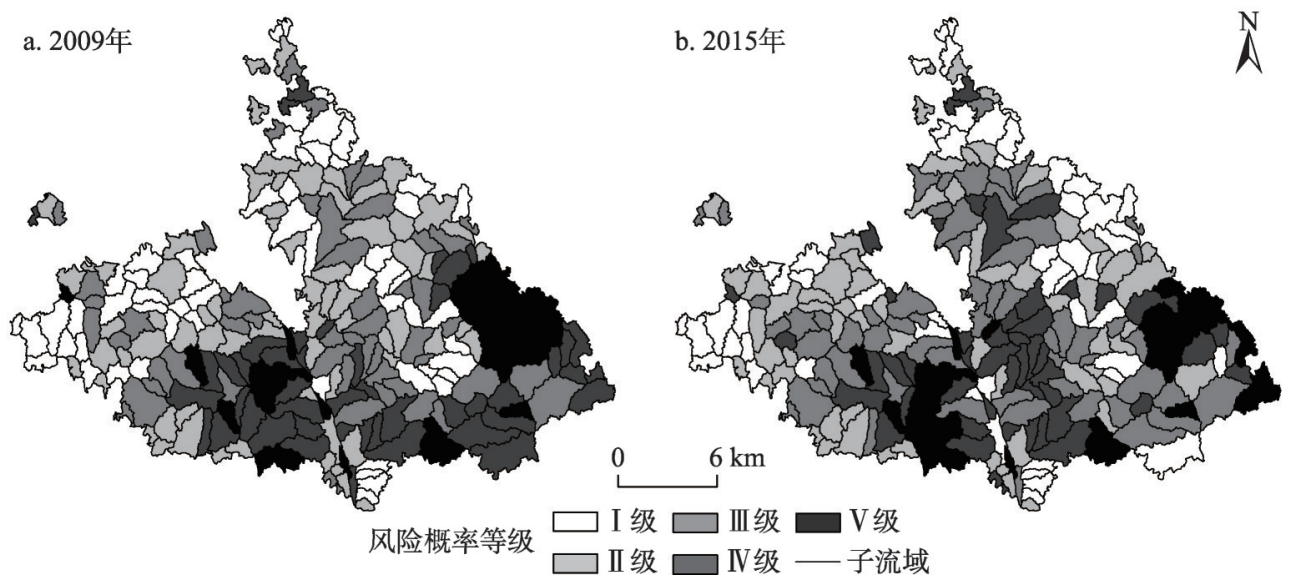

图2 2009年、2015年米脂县风险概率空间分布

Fig. 2 Spatial distribution of risk possibility in Mizhi county in 2009 and 2015 
$11.37 \%$, 集中分布于桃镇与石沟出谷口; 由于较高农药化肥的施用并伴随较高的土地使 用率，桃镇存在较高的农耕生态风险；而石沟为米脂县最大的侵蚀沟，面临较高的洪涝 风险胁迫。IV 级风险概率分布于东南部杨家沟及川道西部的银州，面积占比 $20.86 \%$ 。 I II 级风险概率占 $44.99 \%$ ，分布于西北部; 西部各乡镇农药化肥使用量较低，且西部集 聚大量水库用于年内丰枯的调蓄，故干旱程度较低; 同时北部与西部交通相对闭塞，农 户干扰造成的生态系统服务价值降低的可能性较小。图 $2 \mathrm{~b}$ 中，相较于 2009 年，研究期末 风险概率呈现向西北部移动并在中部扩张的整体趋势。研究区东南部风险概率缩小，由 于桃镇等乡镇农药化肥的施用有所降低, 土壤污染得到明显减轻; 西北部风险概率面积 的扩大与石沟、高渠土壤污染的升高, 与沙店和石沟道路扩张有明显的关系。

\section{1 .2 生境敏感性时空分异}

米脂县 2009 年、 2015 年敏感性分别为 $0.61 、 0.60$ ，下降 $1.6 \%$ 。图 3a中，I级敏感性 位于东北与东南的山地区域, 面积较小; II 级敏感性分布于西部及东部丘陵冠顶, 面积 占比 $26.38 \%$ 。总体上看，I II 级敏感性分布于林草地广布的高海拔区域。区域内保证了 生境的完整，成为生物应对周围环境变化的避难场所，且距离建设用地、道路等景观胁 迫因子较远，系统内具备较好的生态学过程，生境敏感性较小。III级敏感性分布于各大 侵蚀沟谷区，面积分布最广，这类区域虽距人类干扰环境较远，但已处于自然生境可能 被威胁的先锋位置。IV 级敏感性位于中东部、西部榆林风沙区等; 中东部区域伴随长期 土地撂荒，抛荒面积占全县首位，这些未利用地是导致生境退化的重要因子。 $\mathrm{V}$ 级敏感 性几乎全部位于无定河川道，面积占比 $1.63 \%$; 川道区域中建设用地密集区域受人类干 扰最大，且较易发生土壤污染、水土流失等生态事件，生境敏感性最高。图 $3 \mathrm{~b}$ 中，I级 敏感性在东北部、东南部有所扩展，面积比例增至 $17.71 \%$ 。II 级敏感性在西部得到扩 张, 主要由 III 级敏感性转化而来。与此同时, III 级 IV 级敏感性面积分别减小至 $32.55 \% 、 16.73 \%$ ，桃镇的 IV 级敏感性大幅度减小，中部沙店的 III 级敏感性转化为较低 一级。 $\mathrm{V}$ 级敏感性保持期初的空间分布，依然分布于无定河川道，川道生境质量并没有 得到改善，敏感性保持较高水平。

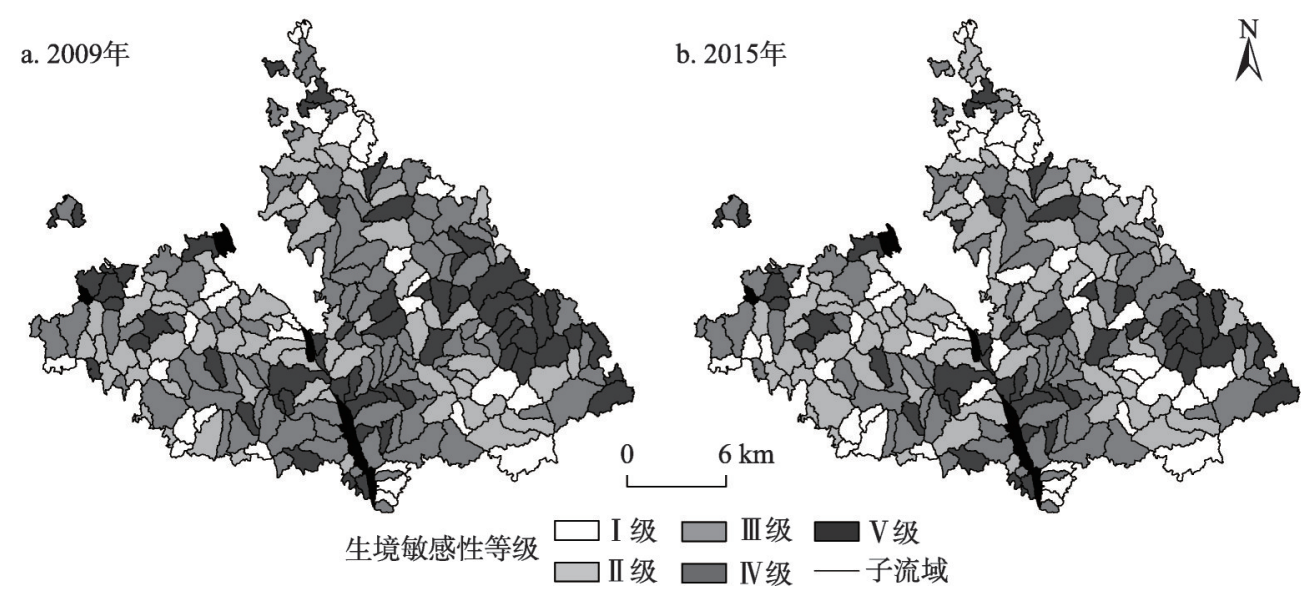

图 3 2009年、2015年米脂县生境敏感性空间分布

Fig. 3 Spatial distribution of habitat sensitivity in Mizhi county in 2009 and 2015 


\section{1 .3 系统损失度时空分异}

米脂县 2009 年、 2015 年损失度分别为 $0.42 、 0.46$ ，整体上升 $9.5 \%$ 。图 4 中，米脂县 损失度呈现中西部高，东部低的空间格局。图 $4 \mathrm{a}$ 中，I级损失度位于东北、东南，面积 集中，区域距离米脂县城区较远，人口密度有限；同时位于丘陵山区，粮食产量较低， 故社会经济损失度较低。IV V 级损失度片状直线分布于中部并向东西方向延伸，面积占 比 $22.82 \%$ ，分布区域如下：东部的桃镇由于耕地撂荒面积较大导致景观无序性升高，荒 地降低了生态系统抵抗外部干扰的弹性能力; 西部的郭兴庄靠近风沙过渡区，土壤风蚀 沙化明显, 林草地破碎, 景观分离度较高, 自然损失度全县最高; 川道人口密度较高、 同时也是米脂县最大的农耕灌区，故社会经济损失度较高。图 $4 \mathrm{~b}$ 中，损失度呈现中部聚 集的主要趋势。I 级损失度明显减少, 位于东南部的 I级损失度多转化为 II 级, 面积减少 至 $11.85 \%$ 。 II 级损失度基本维持不变，研究期间一部分 II 级损失度由 I级转化而来，同时 又转出为 III 级, 故面积保持稳定, 仅上升了 $3.85 \%$ 。 IV V 级损失度由分散趋向于向川道 集中，银州将面临更为严重的风险损失度。

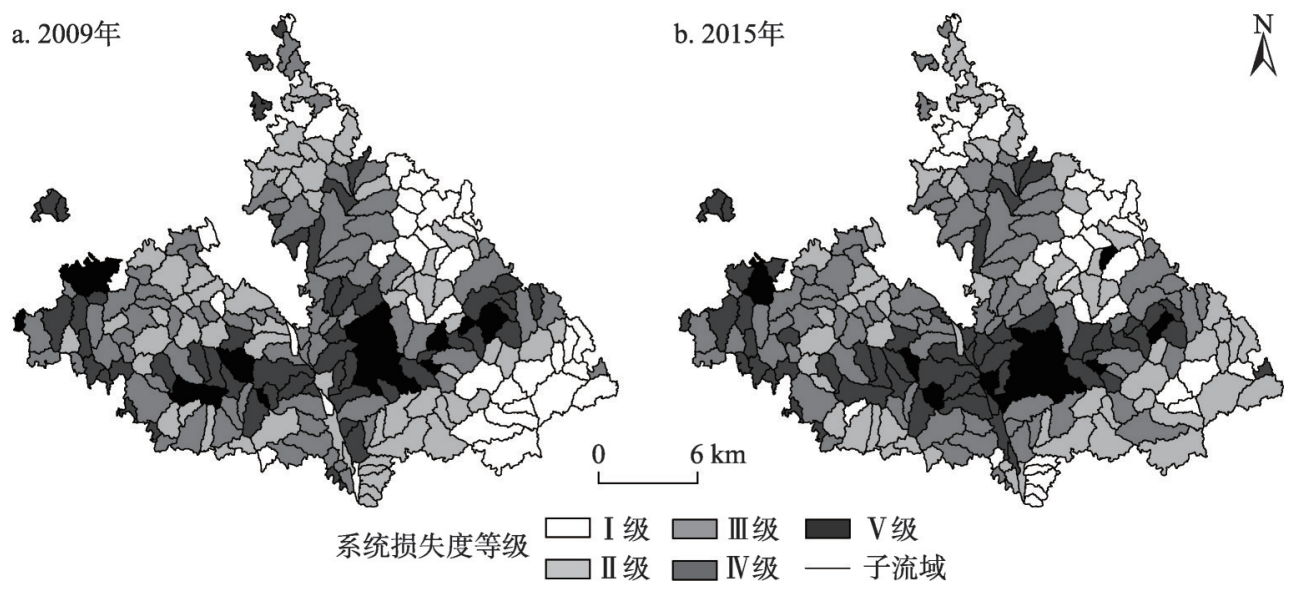

图 4 2009年、2015年米脂县风险损失度空间分布

Fig. 4 Spatial distribution of impartment in 2009 and 2015 in the Mizhi county

\section{2 综合生态风险时空分异}

\section{2 .1 综合生态风险的时空分布}

米脂县 2009 年、 2015 年生态风险分别为 $0.14 、 0.15$ ，上升 $7.14 \%$ 。利用风险转移矩 阵说明风险的变化情况（表 5)。表 5 中，除面积不变的风险等级之外，风险转移类型涉 及 I II 等 4 类等级增加的转移类型及 II I 等 4 类等级减小的类型。经过数理统计，风险等 级由低到高转变的面积有 $26327 \mathrm{hm}^{2}$, 占研究区总面积的 $22.35 \%$, 而反向转变面积为 $16215 \mathrm{hm}^{2}$ ，面积占比 $13.76 \%$ ，说明在局部区域风险有所下降，而在整体上呈上升趋势。

由图 5 可知，生态风险空间差异显著，呈现中高北低的空间格局。图 5a 中，I II 级 风险占比 $52.92 \%$, 分布于东南部、东北部; III 级风险分布于 IV V 级风险周围, 面积占 比 $26.10 \%$; IV V 级风险分布较为分散，主要位于东部桃镇、西部石沟出谷口及桥河 岔, 被 III 级风险隔开, 面积占比 $20.97 \%$ 。图 5b 中, 2015 年生态风险等级面积变化较 大, 生态风险增加。I级风险减少 $2051 \mathrm{hm}^{2}$, 变化主要发生在东南部、西北部; II 级风险 
表 52009 年、2015 年米脂县综合生态风险转移矩阵

Table 5 Transition matrix of comprehensive ecological risk in Mizhi county in 2009 and 2015

$\left(\mathrm{hm}^{2}\right)$

\begin{tabular}{lccccccc}
\hline 生态风险等级 & I & II & III & IV & V & 2015 年面积总计 & 2015 年面积比例 $/ \%$ \\
\hline I & 17122 & 2844 & & & & 19966 & 17.36 \\
II & 4895 & 26552 & 411 & & & 31859 & 22.48 \\
III & & 9455 & 17320 & 2210 & & 28985 & 29.55 \\
IV & & 13292 & 12957 & 588 & 26837 & 22.46 \\
V & & & 3131 & 7032 & 10163 & 8.14 \\
2009年面积总计 & 22017 & 38852 & 31023 & 18298 & 7620 & 117809 & 100 \\
2009年面积比例/\% & 19.14 & 33.78 & 26.10 & 15.04 & 5.93 & & \\
面积净变化 & -2051 & -6993 & -2038 & 8539 & 2543 & & \\
\hline
\end{tabular}



图 5 2009年、2015 年米脂县综合生态风险空间分布

Fig. 5 Spatial distribution of comprehensive ecological risk in Mizhi county in 2009 and 2015

减少 $6993 \mathrm{hm}^{2}$, 是风险变化面积最大 的等级类型； III 级风险面积减少 $6.57 \%$, 变化主要发生在川道周边; $\mathrm{IV} \sim \mathrm{V}$ 级风险面积分别增加了 $46.67 \%$ 、 $33.37 \%$ ，已在中部呈现集聚。

\subsection{2 风险重心的空间跃迁}

基于 ArcGIS 10.2 方向分布工具 生成 2009 年、 2015 年米脂县风险标 准差椭圆并提取风险重心，结果如图 6 所示，标准差粗圆各项参数如表 6 所示。对比 2009 年、2015 年米脂县 风险椭圆特征值与覆盖范围测度结果 (表 6), 以正北方向为 0 , 可以看出 研究期间风险椭圆旋转角在 $96.69^{\circ}$

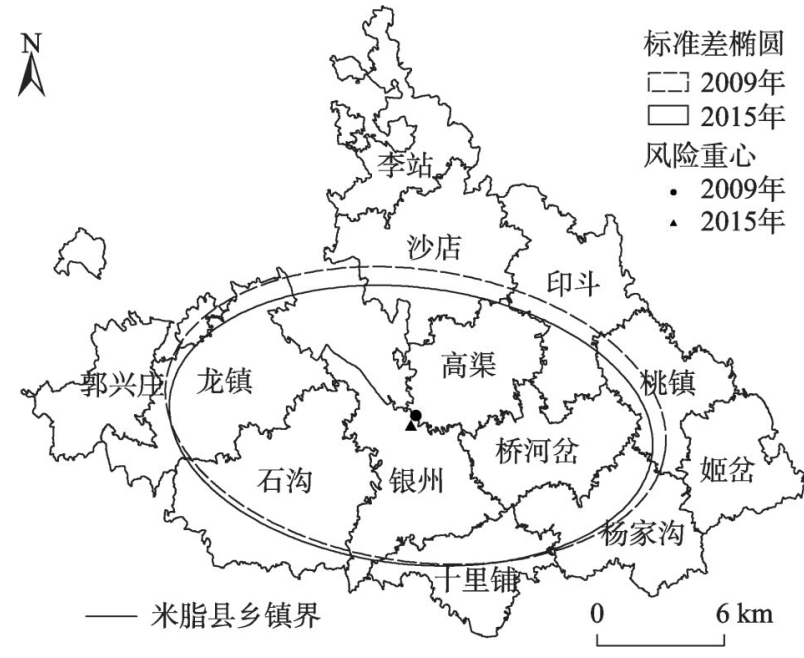

图6 生态风险标准差椭圆及重心变化

Fig. 6 Change of standard ellipse and risk gravity of $C E R$ 
表 6 标准差椭圆及重心参数

Table 6 Parameters of standard ellipse and risk gravity

\begin{tabular}{|c|c|c|c|c|c|}
\hline \multirow{2}{*}{ 年份 } & \multicolumn{3}{|c|}{ 风险重心 } & \multirow{2}{*}{ 扁率 } & \multirow{2}{*}{ 旋转角/ } \\
\hline & 经度 & 纬度 & 移动方向 & & \\
\hline 2009 & $110^{\circ} 9^{\prime} 13^{\prime \prime E}$ & $37^{\circ} 48^{\prime} 32^{\prime \prime} \mathrm{N}$ & - & 0.42 & 98.20 \\
\hline 2015 & $110^{\circ} 8^{\prime} 59^{\prime \prime} \mathrm{E}$ & $37^{\circ} 48^{\prime} 70^{\prime \prime} \mathrm{N}$ & 西南 & 0.43 & 96.69 \\
\hline
\end{tabular}

$98.20^{\circ}$ 之间，变化幅度较小，说明风险演化的主体方向大致为西北一东南走向，且基本 保持稳定。研究期间椭圆扁率由 0.42 上升至 0.43 , 说明风险值在由分散向中心集聚的过 程中其风险长轴的方向性更加明显。图 6 中, 风险重心在高渠乡西南，2015 年向西南移 动, 重心跃人银州川道。随着社会经济发展, 川道区域汇聚各个乡镇的人口, 人口密度 大幅度提高; 同时粮食产量、化肥农药污染等均较高，且最易发生洪涝风险，研究期末 保持较高的损失度与风险可能性。与 2009 年相比, 2015 年生态风险标准差椭圆呈现缩小 趋势，说明生态风险由分散得以集聚，空间趋同性及集聚显著性有所增强。

\subsection{3 风险防范分区及降险对策}

根据风险因子组合特征生成基于子流域的风险防范分区并示于图 7。统计表明，风 险预警区、生态恢复区、预警恢复兼顾区、自然调控区面积占比分别为 $7.53 \%$ 、6.57\%、 $23.86 \%$ 、62.04\%。风险预警区主要分布于川道两侧，部分位于桃镇、石沟; 生态恢复区 面积较小，主要分布于西部的郭兴庄、川道及东部部分区域; 预警恢复兼顾区是风险防 范的关键区域，主要分布于石沟、桥河岔、桃镇、沙店等乡镇。

风险防范分区可探究风险发生的内在作用机制，能够更加针对性地提出防范措施， 达到降险目的。针对风险预警区, 需认清自然灾害与农耕胁迫营造的风险环境：一方 面，基于 $R S$ 进行灾害排查，划定风险孕灾区，关注退耕还林施行成效、坡耕地退耕、河 流汗期监控等方面，建设淤地坝、修复病险坝以减少洪涝发生频次。水是黄土高原农户 生计的持续根本，必须加强对水域的保护，合理进行农业灌溉并利用洪水进行农业年内 丰枯的调蓄。另一方面, 关注农药化 肥施用情况，下派农技人员进行基层 农技培训以提高施肥效率, 开展高效 率、可持续的农业发展模式。针对生 态恢复区, 需认清胁迫源对敏感受体 的作用条件。一方面, 合理规划乡镇 用地, 关注生态修复, 防止地面塌陷 引致的土壤侵蚀。山区道路建设中着 力铺设硬化道路以减弱路面侵蚀, 加 强道路绿化建设以减避水土对道路的 掩埋。合理进行乡镇扩张，严禁斩坡 取土, 对高坡度开挖土地进行硬化并 围挡。另一方面, 增加林草地面积, 减少耕地的同时转变农业种植结构, 大力发展林果业等经济作物规模, 以

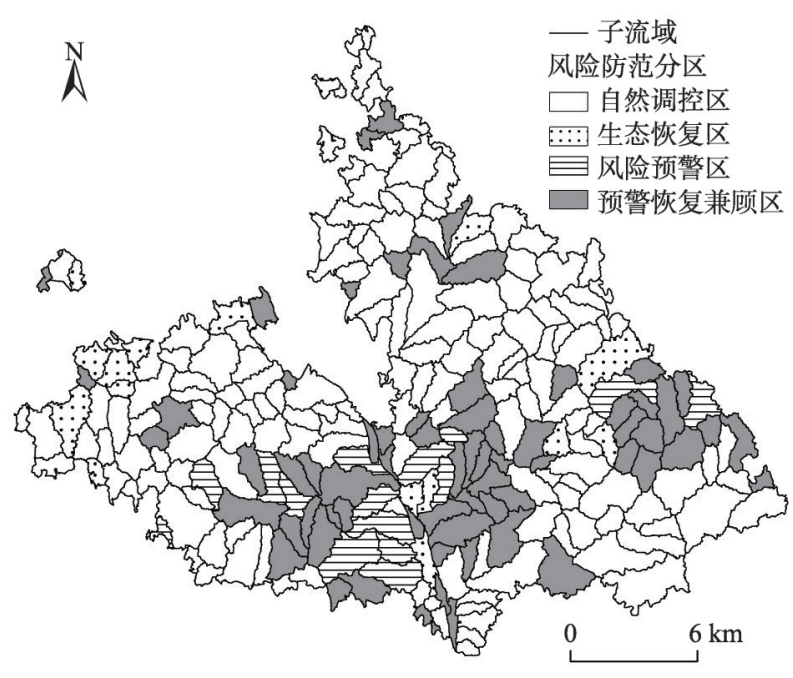

图 7 基于子流域的风险防范分区

Fig. 7 Risk precaution partitions at watershed level 
合作经济组织带动转变农业生产方式, 进一步降低生境敏感性。针对预警恢复兼顾区, 应兼顾上述两方面风险防范策略。针对自然调控区，属于风险防范冷点，暂不需要进行 过多人为防治措施，重点借助生态系统自身恢复力实现风险的自然调控。

\section{3 结论与讨论}

\section{1 结论}

（1）米脂县风险概率呈现西北部低、中部与东部较高的空间格局，且研究期间风险 概率分别为 $49.93 \%$ 、52.92\%，有上升趋势；研究期间生境敏感性分别为 $0.61 、 0.60$ ，下 降了 $1.6 \%$ ，生境质量趋好；损失度呈现中部与西部较高，东部较低的空间格局，研究期 间损失度分别为 $0.42 、 0.46$ ，有增加趋势。

（2）综合生态风险呈现中间高南北低的空间分布格局；研究期间综合风险分别为 0.14、0.15。风险重心由高渠乡西南跃人银州川道; 风险演化的主体方向大致为西北一东 南走向并保持稳定。

（3）风险预警区、生态恢复区、预警恢复兼顾区、自然调控区分别占研究区面积的 $7.53 \%$ 、6.57\%、23.86\%、62.04\%。基于风险主导因子的风险防范分区可有效进行风险消 解, 促进区域生境的可持续。

\section{2 讨论}

本文基于经典的概率一损失二维框架，通过生境敏感性链接风险源汇，建立风险概 率一敏感性一损失度的三维风险框架，可进一步完善风险因果链，为生态风险的定量化 提供了一定的理论支撑；基于评价结果的风险防范分区研究及降险策略从自然环境恢 复、社会经济转型等角度，为黄土沟壑区风险消解和生境恢复提供科学指引。

作为典型的生态脆弱区与国家贫困县，米脂县农耕发展与脆弱的自然本底作为一组 权衡对子，使区域可持续发展成为困局。自然灾害频发与人口的不断外迁，影响区域经 济的持续并降低人们的地方认同感，同时经济能力有限而难以搬迁的农户则面临诸多生 计问题：干早造成农业减产甚至绝收、乡村道路的冲毁阻断了居民点与城镇之间的交 流、洪涝使得坝地盐碱地增加，致使此类农户不断拓荒以应对生计胁迫，从而陷人贫困 循环并威胁区域生境。以生态风险为诱因的诸多社会现象对社会一生态系统可持续发展 与农户福祉的提升影响巨大，加之农户是造成区域土地利用变化的主要因子，是人地系 统中最主要的经济活动主体，因此以异质性农户的视角关联个体生计并关注农户福祉水 平，在风险评价框架中充分体现农户社会经济层次对相关风险要素的贡献程度，并发挥 农户在农耕区风险消解过程中的主导作用，将是下一步风险评估研究的重点。

\section{参考文献(References):}

[1] 傅伯杰. 地理学: 从知识、科学到决策. 地理学报, 2017, 72(11): 1923-1932. [FU B J. Geography: From knowledge, science to decision making support. Acta Geographica Sinica, 2017, 72(11): 1923-1932.]

[2] 彭建, 党威雄, 刘炎序, 等. 景观生态风险评价研究进展与展望. 地理学报, 2015, 70(4): 664-677. [PENG J, DANG W X, LIU Y X, et al. Review on landscape ecological risk assessment. Acta Geographica Sinica, 2015, 70(4): 664-677.]

[3] 张小飞, 彭建, 王仰麟, 等. 全球变化背景下景观生态适应性特征. 地理科学进展, 2017, 36(9): 1167-1175. [ZHANG H F, PENG J, WANG Y L, et al. Characteristics of landscape system in the context of global change. Progress in Geography, 2017, 36(9): 1167-1175.]

[4] 徐兰, 罗维, 周宝同. 基于土地利用变化的农牧交错带典型流域生态风险评价: 以洋河为例. 自然资源学报, 2015, 30 
(4): 580-590. [XU L, LUO W, ZHOU B T. Landscape ecological risk assessment of farming-pastoral ecozone based on land use change: A case study of the Yanghe Watershed, China. Journal of Natural Resources, 2015, 30(4): 580-590.]

[5] 杜悦悦, 彭建, 赵士权, 等. 西南山地滑坡灾害生态风险评价: 以大理白族自治州为例. 地理学报, 2016, 71(9): 15441561. [DU Y Y, PENG J, ZHAO S Q, et al. Ecological risk assessment of landslide disasters in mountainous areas of Southwest China: A case study in Dali Bai Autonomous Prefecture. Acta Geographica Sinica, 2016, 71(9): 1544-1561.]

[6] MIRZABEYGI M, ABBASNIA A, YUNESIAN M, et al. Heavy metal contamination and health risk assessment in drinking water of Sistan- and-Baluchistan, Southeastern Iran. Human and Ecological Risk Assessment, 2017, 23(8): 1893-1905.

[7] KICINSKA A, MAMAK M. Health risks associated with municipal waste combustion on the example of Laskowa Commune (Southern Poland). Human and Ecological Risk Assessment, 2017, 23(8): 2087-2096.

[8] 汪翡翠, 汪东川, 张利辉, 等. 京津冀城市群土地利用生态风险的时空变化分析. 生态学报, 2018, 38(12): 4307-4316. [WANG F C, WANG D C, ZHANG L H, et al. Spatiotemporal analysis of the dynamic changes in land use ecological risks in the urban agglomeration of Beijing-Tianjin-Hebei region. Acta Ecologica Sinica, 2018, 38(12): 4307-4316.]

[9] 曹祺文, 张曦文, 马洪坤, 等. 景观生态风险研究进展及基于生态系统服务的评价框架: ESRISK. 地理学报, 2018, 73 (5): 843-855. [CAO Q W, ZHANG X W, MA H K, et al. Review of landscape ecological risk and an assessment framework based on ecological services: ESRISK. Acta Geographica Sinica, 2018, 73(5): 843-855.]

[10] MALEKMOHAMMADI B, RAHIMA BLOUCHI L. Ecological risk assessment of wetland ecosystems using Multi Criteria Decision Making and Geographic Information System. Ecological Indicators, 2014, 41(6): 133-144.

[11] 彭建, 谢盼, 刘炎序, 等. 低丘缓坡建设开发综合生态风险评价及发展权衡: 以大理白族自治州为例. 地理学报, 2015, 70(11): 1747-1761. [PENG J, XIE P, LIU Y X, et al. Integrated ecological risk assessment and spatial development trade-offs in low-slope hilly land: A case study in Dali Bai Autonomous Prefecture, China. Acta Geographica Sinica, 2015, 70(11): 1747-1761.]

[12] 李谢辉, 王否, 李景宜. 基于 GIS 的渭河下游河流沿线区域生态风险评价. 生态学报, 2009, 29(10): 5523-5534. [LI X H, WANG L, LI J Y. Regional ecological risk assessment in catchment area along the Weihe River based on GIS. Acta Ecologica Sinica, 2009, 29(10): 5523-5534.]

[13] 刘春艳, 张科, 刘吉平. 1976-2013 年三江平原景观生态风险变化及驱动力. 生态学报, 2018, 38(11): 3729-3740. [LIU C Y, ZHANG K, LIU J P. A long-term site study for the ecological risk migration of landscapes and its driving forces in the Sanjiang Plain from 1976 to 2013. Acta Ecologica Sinica, 2018, 38(11): 3729-3740.]

[14] 徐羽, 钟业喜, 冯兴华, 等. 鄱阳湖流域土地利用生态风险格局. 生态学报, 2016, 36(23): 7850-7857. [XU Y, ZHONG Y X, FENG X H, et al. Ecological risk pattern of Poyang Lake Basin based on land use. Acta Ecologica Sinica, 2016,36 (23): 7850-7857.]

[15] 赵岩洁, 李阳兵, 邵景安. 基于土地利用变化的三峡库区小流域生态风险评价: 以草堂溪为例. 自然资源学报, 2013, 28(6): 944-956. [ZHAO Y J, LI Y B, SHAO J A. Ecological risk assessment of small watershed of the Three Gorges Reservoir Area based on land use change: A case study of Caotang River. Journal of Natural Resources, 2013, 28 (6): 944-956.]

[16] 许妍, 高俊峰, 郭建科. 太湖流域生态风险评价. 生态学报, 2013, 33(9): 2896-2906. [XU Y, GAO J F, GUO J K. The ecological risk assessment of Taihu Lake watershed. Acta Ecologica Sinica, 2013, 33(9): 2896-2906.]

[17] 周汝佳, 张永战, 何华春. 基于土地利用变化的盐城海岸带生态风险评价. 地理研究, 2016, 35(6): 1017-1028. [ZHOU R J, ZHANG Y Z, HE H C. Ecological risk assessment based on land use changes in the coastal area in Yancheng city. Geographical Research, 2016, 35(6): 1017-1028.]

[18] LI J L, PU R L, GONG H B, et al. Evolution characteristics of landscape ecological risk patterns in coastal zones in Zhejiang province, China. Sustainability, 2017, 9, 584.

[19] 吴健生, 乔娜, 彭建, 等. 露天矿区景观生态风险空间分异. 生态学报, 2013, 33(12): 3816-3824. [WU J S, QIAO N, PENG J, et al. Spatial variation of landscape eco-risk in open mine area. Acta Ecologica Sinica, 2013, 33(12): 38163824.]

[20] 张学斌, 石培基, 罗君, 等. 基于景观格局的干旱内陆河流域生态风险分析: 以石羊河流域为例. 自然资源学报, 2014, 29(3): 410-419. [ZHANG X B, SHI P J, LUO J, et al. The ecological risk assessment of arid inland river basin at 
the landscape scale: A case study on Shiyang River Basin. Journal of Natural Resources, 2014, 29(3): 410-419.]

[21] 刘炎序, 王仰麟, 彭建, 等. 基于生态适应性循环三维框架的城市景观生态风险评价. 地理学报, 2015, 70(7): 10521067. [LIU Y X, WANG Y L, PENG J, et al. Urban landscape ecological risk assessment based on the 3D framework of adaptive cycle. Acta Geographica Sinica, 2015, 70(7): 1052-1067.]

[22] LIU D, LIANG X Y, CHEN H, et al. A quantitative assessment of comprehensive ecological risk for a loess erosion gully: A case study of Dujiashi Gully, Northern Shaanxi province, China. Sustainability, 2018, 10: 3239.

[23] PENG J, ZONG M L, HU Y N, et al. Assessing landscape ecological risk in a mining city: A case study in Liaoyuan city, China. Sustainability, 2015, 7(7): 8312-8334.

[24] 虞燕娜, 朱江, 吴绍华, 等. 多风险源驱动下的土地生态风险评价: 以江苏省射阳县为例. 自然资源学报, 2016, 31 (8): 1264-1274. [YU Y N, ZHU J, WU S H, et al. Assessment of land ecological risks driven by multi-sources: A case study of Sheyang county, Jiangsu province. Journal of Natural Resources, 2016, 31(8): 1264-1274.]

[25] 张小飞, 王如松, 李正国, 等. 城市综合生态风险评价: 以淮北市城区为例. 生态学报, 2011, 31(20): 6204-6214. [ZHANG H F, WANG R S, LI Z G, et al. Comprehensive assessment of urban ecological risks: The case of Huaibei city. Acta Ecologica Sinica, 2011, 31(20): 6204-6214.]

[26] 巫丽芸, 何东进, 游巍斌, 等. 福建东山岛灾害生态风险的时空演化. 生态学报, 2016, 36(16): 5027-5037. [WU L Y, HE D J, YOU W B, et al. Disaster ecological risk assessment in Dongshan Island: Spatio-temporal evolution. Acta Ecologica Sinica, 2016, 36(16): 5027-5037.]

[27] 刘迪, 陈海, 梁小英, 等. 黄土丘陵沟壑区生态风险动态变化及其地形梯度分析: 以陕西省米脂县为例. 生态学报, 2018, 38(23):8584-8592. [LIU D, CHEN H, LIANG X Y, et al. The dynamic changes to ecological risk in the Loess Hilly-gully Region and its terrain gradient analysis: A case study of Mizhi county, Shaanxi province, China. Acta Ecologica Sinica, 2018, 38(23): 8584-8592.]

[28] WANG Z T, YANG L, CAI G J, et al. A quantitative health evaluation of an eco-economy in the Semi-arid Loess Plateau of China. Human and Ecological Risk Assessment, 2015, 21(7): 1884-1902.

[29] 李景刚, 何春阳, 李晓兵. 快速城市化地区自然半自然景观空间生态风险评价研究: 以北京为例. 自然资源学报, 2008, 23(1): 33-47. [LI J G, HE C Y, LI X B. Landscape ecological risk assessment of natural/semi-natural landscape sin fast urbanization regions: A case study in Beijing, China. Journal of Natural Resources, 2008, 23(1): 33-47.]

[30] WONG C P, JIANG B, KINZIG A P, et al. Linking ecosystem characteristics to final ecosystem services for public policy. Ecology Letters, 2015, 18(1): 108-118.

[31] 刘春芳, 王川, 刘立程. 三大自然区过渡带生境质量时空差异及形成机制: 以榆中县为例. 地理研究, 2018, 37(2): 419-432. [LIU C F, WANG C, LIU L C. Spatio-temporal variation on habitat quality and its mechanism within the transitional area of the Three Natural Zones: A case study in Yuzhong county. Geographical Research, 2018, 37(2): 419432.]

[32] 吴健生, 曹祺文, 石淑芹, 等. 基于土地利用变化的京津冀生境质量时空演变. 应用生态学报, 2015, 26(11): 34573466. [WU J S, CAO Q W, SHI S Q, et al. Spatio-temporal variability of habitat quality in Beijing-Tianjin-Hebei area based on land use change. Chinese Journal of Applied Ecology, 2015, 26(11): 3457-3466.]

[33] RICHARD S, REBECCA C K, SPENCER W. InVEST 3.3.0 User's Guide. http://data.naturalcapitalproject.org/ nightlybuild/invest-users-guide/html/habitatquality.html, 2015.

[34] 梅亚军. 生态脆弱区景观服务定量化及综合评价研究. 西安: 西北大学, 2017. [MEI Y J. The study on the quantification and integrated assessment of landscape services in the fragile area: The study of Mizhi county of Shannxi province. Xi'an: Northwest University, 2017.]

[35] XIE H L, WANG P, HUANG H S. Ecological risk assessment of land use change in the Poyang Lake eco-economic zone, China. International Journal of Environmental Research and Public Health, 2013, 10(1): 328-346. 


\title{
Spatio-temporal variation of ecological risk in the loess hilly-gully region and its precaution partitions: A case study of Mizhi county, Shaanxi province, China
}

\author{
LIU Di, CHEN Hai, SHI Qin-qin, ZHANG Hang, GENG Tian-wei \\ (College of Urban and Environmental Science/Shaanxi Key Laboratory of Earth Surface System and \\ Environmental Carrying Capacity, Northwest University, Xi'an 710127, China)
}

\begin{abstract}
Ecologically fragile regions such as loess hilly-gully region are highly responsive to global change. Regional development is on an unsustainable track under the background of fragile ecological environment and agricultural activities. The study of ecological risk in this region has become one of the hot spots of geographical and ecological response to ecosystem management. Taking Mizhi county for the study of loess hilly-gully region, land-use maps of this county in 2009 and 2015, a digital elevation model (DEM) and social and economic statistical yearbook of Mizhi county were needed and 253 small watersheds were identified as the auxiliary evaluation units by using ESRI's Hydrological Analysis Tools for ArcGIS 10.2. A comprehensive ecological risk assessment framework for identifying risk probability, habitat sensitivity, and system impairment was established, and multi- source data were integrated through range standardization and entropy weight method at watershed level. The spatiotemporal differentiation of criteria layers and comprehensive ecological risk were analyzed, at the same time, the evolution trend of comprehensive ecological risk was explored through the Standard Deviation Ellipse (SDE) and risk gravity. The risk precaution partitions were simultaneously delineated based on the risk dominant factor and the risk management strategies were formulated. The results were as follows: (1) The spatial distribution pattern of risk probability in Mizhi county was generally high in the middle and east and low in the northwest. The value of risk probability increased from $49.93 \%$ to $52.92 \%$ during $2009-2015$. The habitat sensitivity index was 0.61 in 2009 and 0.60 and 2015, respectively, which was a decrease of $1.6 \%$ based on the InVEST model, and the habitat quality improved. The system impairment index was generally higher in the central and western regions while lower in the eastern region (southeast and northeast). The impairment index increased from 0.42 to 0.46 during 2009-2015, which indicated that the degree of impairment caused by ecological risk increased. (2) The spatial distribution pattern of comprehensive ecological risk was high in the middle, while low in the south and north. Between 2009 and 2015, the ecological risk index increased from 0.14 to 0.15 , with an increase of $7.14 \%$. The risk gravity of Mizhi county was distributed in Gaoqu township in 2009, and jumped into Yinzhou township in 2015. The main ecological risk evolution was northwest-southeast trending, and kept stable basically. (3) The study area was divided into four types of risk precaution partitions. Risk monitoring zones, ecological recovery zones, monitoring and recovery zones, and natural regulation zones encompassed $7.53 \%$, $6.57 \%, 23.86 \%$ and $62.04 \%$ of the study area, respectively. Risk precaution partitions based on risk dominant factors can effectively eliminate risks and promote the sustainable development of regional habitats.
\end{abstract}

Keywords: ecological risk; spatio-temporal differentiation; risk gravity; risk precaution partitions; Mizhi county; loess hilly-gully region 